\title{
O terrário como temática no ensino de ciências na educação do campo
}

\author{
The terrarium as theme in science teaching in the field of education
}

\author{
Layanne Nayara de Moura1, Laylla Natália de Mouraํ, Ronaldo Eustáquio Feitoza Senra², Isabela \\ Codolo de Lucena ${ }^{3}$, Geison Jader Mello ${ }^{4}$ \\ 1 Licenciadas em Ciências da Natureza, Núcleo Avançado de Jaciara - campus São Vicente - IFMT, Jaciara - MT, Brasil
2 Doutor em Educação, Núcleo Avançado de Jaciara - campus São Vicente - IFMT, Jaciara - MT, Brasil
3 Doutora em Ciências, Núcleo Avançado de Jaciara - campus São Vicente - IFMT, Jaciara - MT, Brasil
4 Doutor em Física Ambiental, Núcleo Avançado de Jaciara - campus São Vicente - IFMT, Jaciara - MT, Brasil
}

\section{Resumo}

As aulas práticas contribuem para uma aprendizagem significativa dentro do Ensino de Ciências. Estas aulas além de se tornarem atividades diferenciadas do ensino tradicional, contribuem para inovar o processo de ensino-aprendizagem na Educação Básica. Este trabalho foi desenvolvido na Escola Estadual Senador Filinto Muller, distrito de Irenópolis, município de Juscimeira/ MT, sendo considerada uma escola do campo com aproximadamente 120 discentes. Desta maneira, o referido trabalho teve como objetivo avaliar se a construção de terrários pode ser indicada como prática de ensino que propicia a aprendizagem significativa dos discentes no Ensino de Ciências. O terrário foi estruturado e montado com a participação dos discentes e professores. Com os resultados, verificou-se que a confecção de terrários pode ser um instrumento para tornar o ensino de Ciências mais criativo, dinâmico, possibilitando aos discentes a capacidade de observação, análise e de construção dos seus próprios conhecimentos científicos sobre as vidas existentes em um ecossistema. Outro resultado identificado foi a motivação e a participação efetiva dos discentes nas aulas práticas. No contexto de uma escola do campo, a relação entre o ensino de Ciências e a realidade a qual a escola está inserida possibilitou a vivência e a aprendizagem significativa.

Palavras-Chaves: Terrário. Ensino de ciências. Educação do campo

\begin{abstract}
Practical studies contribute to a meaningful learning for Science Education. Besides becoming different activities from traditional teaching, these studies contribute to innovate the process of teaching and learning in elementary education. This work was developed in the State School Senador Filinto Muller, Irenópolis district of Juscimeiral MT, considered a field school with 120 students. This stydy investigated if the construction of terrariums can be indicated as teaching practice that provides meaningful learning for students in Science Teaching. The terrarium was built with the participation of students and teachers. It was confirmed that terrariums can be an instrument to become the teaching more creative and dynamic, enabling students to develop the ability of observation, analysis and construction of their own scientific knowledge about ecosystem. It was also identified motivation and effective participation of students during the practical studies. In the context of school field, the relationship between the teaching of Science and the reality which the school is inserted enabled the living and meaningful learning.
\end{abstract}

Keywords: Terrarium. Science Teaching. School field 


\section{Introdução}

O Ensino de Ciências na Educação Básica é fundamental para que o discente possa fazer a leitura científica do seu universo vivencial. Esta leitura possibilita uma melhor compreensão dos fenômenos naturais, construindo uma aprendizagem sobre a biodiversidade e mais qualidade de vida.

No entanto, é perceptível a carência de aulas diferenciadas que busque o interesse dos discentes em detrimento a predominância de aulas tradicionais com livros didáticos. Sendo assim surgiu a ideia da construção do Terrário no intuito de proporcionar aos discentes aulas mais atrativas dentro do ensino de Ciências, incentivando a participação dos mesmos a terem uma esperada aprendizagem significativa. Será que os discentes terão uma aprendizagem significativa, ao sair do tradicional livro didático e ter aulas diferenciadas, com a construção do Terrário como um instrumento de ensino e aprendizagem?

As condições de vida dos seres humanos exigem reflexões centradas nas inter-relações entre saberes e práticas estabelecendo uma relação com a natureza. Por isso é importante a busca pelo entendimento da relação entre os seres vivos com o meio em que se vive. Cada ser vivo tem sua função na natureza, eles são capacitados para cumpri-la, seja grande ou pequenos todos têm um papel importante no meio ambiente.

A construção do Terrário foi desenvolvida com os discentes do Ensino Fundamental no Programa Mais Educação e com a Educação de Jovens e Adultos (EJA) do segundo segmento ( $8^{\circ}$ e $9^{\circ}$ ano), sendo utilizado como uma prática para embasar os conteúdos de Ciências. A perspectiva é proporcionar a elaboração de um material didático-pedagógico permanente para a escola, contribuindo para o Ensino de Ciências.

O Terrário é a representação de um ecossistema natural, que é o conjunto de fatores bióticos e abióticos que se encontra em uma determinada região. Por isto, a elaboração de atividades como esta contribui para fortalecer uma Educação do Campo nas suas especificidades, no seu contexto cultural e natural. O Terrário é um instrumento para tornar o Ensino de Ciências mais criativo, dinâmico, possibilitando aos discentes, através de observações e análise, construírem seu conhecimento. Essa atividade torna o professor um orientador, auxiliando os discentes a observar e pesquisar, investigar e construir sua própria conclusão sobre o assunto Terrário.

Este trabalho teve como objetivo utilizar a construção do Terrário como motivação de ensinoaprendizagem no Ensino Fundamental e na EJA e verificar em que medida as aulas práticas contribuem para ampliar os conceitos científicos dos discentes. Outro objetivo é propiciar a observação científica sobre os fenômenos decorrentes do Terrário, construir um ecossistema como forma de laboratório vivo para observar interações ecológicas, apreender conceitos e funcionamentos de um sistema natural ao relacionar o conteúdo de ciências com o cotidiano dos discentes. Por ser uma escola do campo, o potencial de correlação entre o conhecimento popular e o científico se entrelaçam.

\section{Fundamentação Teórica}

\subsection{Ensino de Ciências}

Segundo os Parâmetros Curriculares Nacionais - PCN's (BRASIL,1998), pensar o currículo e o ensino dos conhecimentos científicos das Ciências Naturais é fundamental, mas não suficiente.

A abordagem dos conhecimentos por meio de definições e classificações estanques que devem ser decoradas pelo estudante contraria as principais concepções de aprendizagem (...). Quando há aprendizagem significativa, a memorização de conteúdos debatidos e compreendidos pelo estudante é completamente diferente daquela que se reduz à mera repetição automática de textos cobrada em situação de prova (BRASIL, 1998, p. 26). 
É essencial considerar o desenvolvimento cognitivo dos discentes, relacionado às suas experiências, sua idade, sua identidade cultural, social e ambiental, e os diferentes significados e valores que as Ciências Naturais podem ter para que a aprendizagem seja significativa. Ainda nos $\mathrm{PCN}^{\prime}$ s encontram-se as seguintes orientações:

Em Ciências Naturais, o desenvolvimento de posturas e valores envolve muitos aspectos da vida social, da cultura do sistema produtivo e das relações entre o ser humano e a natureza. (...) Incentivo às atitudes de curiosidade, de persistência na busca e compreensão das informações, de preservação do ambiente e sua apreciação estética, de apreço e respeito à individualidade e à coletividade tem lugar no processo de ensino e aprendizagem. (BRASIL, 1998, pág. 30).

De acordo com Delizoicov et al. (2009), as Ciências Naturais são compostas de um conjunto de explicações com peculiaridades próprias e de procedimentos para obter essas explicações sobre a natureza e os artefatos materiais. Ele ainda diz que o ensino e aprendizagem das Ciências Naturais serão sempre balizados pelo fato de que os sujeitos já dispõem de conhecimentos prévios a respeito do objeto de ensino.

Da mesma forma, é importante buscar métodos de ensino de ciências que construa conhecimento no decurso de observações e experimentos, de maneira a "considerar a ciência como uma série de descobertas e os cientistas como estudiosos que procuram desvendar o desconhecido" conforme descrito no Programa de Ciência exitus enciclopédia ilustrada, 1975, pág. 12. Diante disto, a evolução nas formas do pensamento e os instrumentos, constantemente aperfeiçoados, facilitam e possibilitam a tarefa de ensinar (Programa de Ciências Exitus 1975).

\subsection{Lendo a escola do campo e o processo de ensino-aprendizagem}

De acordo com Paulo Freire (2011), o professor deve deixar transparecer aos educandos que uma das bonitezas de nossa maneira de estar no mundo e com o mundo, como seres históricos, é a capacidade de intervir no mundo, conhecer o mundo. Por isto, ler a Escola do Campo e pensar no processo de ensino-aprendizado é muito mais do que seguir cartilhas e se ter uma educação bancária, conteudística, mas efetivamente partir da leitura de mundo para se chegar ao processo amplo e revolucionário que é o ato de ensinar e aprender dialeticamente. Por isto, o pressuposto é de uma educação dialógica para superar as dificuldades deste processo.

\footnotetext{
A dificuldade dos alunos em compreender os conteúdos escolares é um assunto muito comentado no ambiente escolar por professores de diferentes áreas. Os professores apontam que mesmo após uma explanação supostamente clara do conteúdo, com a utilização de recursos didáticos que pareciam favorecer a aprendizagem, as respostas dadas pelos alunos em atividades utilizadas para avaliação não apresentam os resultados esperados (ZÔMPERO \& LABURÚ 2012, p. 675).
}

Entretanto, se muitos professores acham que apenas explanando os conteúdos de forma que se tenha uma "fácil compreensão", muitos ignoram que o processo de ensino-aprendizagem deve ser dialógico na perspectiva de que não basta expor, dissertar conteúdos e conhecimentos de forma que sua aplicabilidade seja feita por meio de uma ou outra avaliação, mas efetivamente é preciso se ter clareza do papel do professor no processo de ensino-aprendizagem e que o mesmo deve considerar a leitura de mundo de cada contexto. E nesta perspectiva Paulo Freire, afirma:

O professor que desrespeita a curiosidade do educando, o seu gosto estético, a sua inquietude, a sua linguagem, mais precisamente, a sua sintaxe e a sua prosódia; o professor que ironiza o aluno, que o minimiza, que manda que "ele se ponha em seu lugar" o mais tênue sinal de sua rebeldia legítima, tanto quanto o professor que se exime do cumprimento de seu dever de propor limites à liberdade do aluno, que se furta ao dever de ensinar, de estar respeitosamente presente à experiência formadora do educando, transgride os princípios fundamentalmente éticos de nossa existência [...] A boniteza de ser gente se acha, entre outras coisas, nessa possibilidade e nesse dever de brigar. Saber que devo respeito à autonomia e à identidade do educando exige de mim uma prática em tudo coerente com este saber (2011, p. 58). 
Em outra obra o mesmo autor denuncia a postura tradicional e imutável de alguns educadores que alienam a ignorância e, se mantém em posições fixas, invariáveis. Nesta postura, o professor será sempre o que sabe, enquanto os educandos serão sempre o que não sabem. A rigidez destas posições nega a educação e o conhecimento como processo de busca (FREIRE, 2005).

Segundo Kronbauer e Simionato (2008), o modelo de ensino, assim como o modelo de professor assumido pelo sistema educativo e pela sociedade, precisa estar claro tanto para a escola, quanto para os próprios professores. As escolas não podem mudar sem o compromisso dos professores, assim como a educação só evolui tendo legitimadas as práticas que constituem por seus principais interlocutores: os professores, discentes e toda comunidade escolar de um modo geral.

Nesta perspectiva, nas escolas do campo há saberes e conhecimentos que advém daquela realidade e do seu próprio contexto, modo de se fazer educação, superando a visão de "modelo de ensino e de professor", mas efetivando uma busca pelo conhecimento como processo. Assim, acreditamos que para além do giz, do livro e do quadro negro, as escolas do campo possibilitam a produção de saberes e conhecimentos condizentes com suas práticas e leituras de mundo.

\begin{abstract}
As professoras rurais encontram lócus favoráveis à produção de saber social diversificado, ou seja, tornam-se sujeitos de práticas pedagógicas heterogêneas (líderes de associações, produção alimentícia, produção artesanal, etc). Evidencia-se o saber social elaborado para além do espaço escolar, ou seja, em processo educativo diferenciado daquele propiciado pelos instrumentos básicos do saber sistematizado (THERRIEN, 1993, p.47).
\end{abstract}

Ler a escola do campo é perceber os saberes e práticas sociais produzidas no contexto de cada território, comunidade para que o processo de ensino-aprendizagem, principalmente do Ensino de Ciências possa se tornar um processo de aprendizagem significativa e contextualizada, aliando conhecimento científico e popular.

O ensino, mesmo no nível das séries iniciais da escola de $1^{\circ}$ grau, exige do professor, qualificado ou não, habilidade especial no relacionamento com as pessoas, particularmente, com a criança. Também exige uma compreensão mínima do processo de acumulação na obtenção e fixação do conhecimento. Essa habilidade no trato com a criança e essa compreensão empírica do processo pedagógico representa, entre os camponeses, um valioso patrimônio cultural (ALENCAR, 1993, p. 186).

Ao propor a realização de atividades práticas, imersas no território e condizentes com a realidade de cada escola do campo é oportuno para a compreensão de que não poderá haver um processo de ensino-aprendizagem descompromissado e desligado do contexto o qual a escola está inserida.

Mas, efetivamente superando a visão do processo unidirecional da relação "professor transmite o conhecimento ao estudante" e na perspectiva da educação como algo desejável, sonho, e processo de libertação, Rubem Alves (2001) afirma que "dos sonhos saem pássaros selvagens, que nenhuma educação pode domesticar" (p.86). É justamente, superando a visão de escolarização como domesticação é que podemos pensar em um projeto de escola do campo, ou em um processo formativo do campo por meio da escola, aliando a dimensão cultural e ambiental a qual as mesmas estão inseridas.

Na dimensão dialética do processo educativo, Arroyo (2007) afirma que pensar a formação e o projeto da educação do campo é preciso ligar, dar um 'amalgama' destas duas dimensões (cultural e ambiental) e também:

Entender a força que o território, a terra, o lugar tem na formação social, política, cultural, identitária dos povos do campo. Sem as matrizes que se formam sem entender a terra, o território e o lugar como matrizes formadoras, não seremos capazes de tornar a escola um lugar de formação. A articulação entre o espaço da escola e os outros espaços, lugares, territórios onde se reproduzem, será difícil sermos mestres de um projeto educativo (ARROYO, 2007, p. 163). 
Dessa forma, compreender as diversas leituras de mundo o qual os discentes do campo estão imersos, inclusive pela sua territorialidade é, sobretudo superar a visão de que "o discente é uma folha em branco em que são depositados conhecimentos sistematizados durante sua escolarização" (DELIZOICOV et al., 2009). As experiências, explicações e os conceitos que formou e forma, em sua relação mais ampla do que a de escolaridade irá interferir radicalmente na sua aprendizagem em relação ao Ensino de Ciências.

Por isso os professores têm que ter certeza sobre o que ensina aos seus discentes, pois é através do processo dialógico do conhecimento científico e popular que podemos perceber a construção de um processo de ensino-aprendizagem mais significativo.

Para Corrêa (2001), as dificuldades no aprender referem-se aos obstáculos de natureza cognitiva que o sujeito encontra para superar os desequilíbrios. A resposta dada pelo discente, diante da realidade, pode ser lógica e semelhante a dos outros colegas, mas muitas vezes é diferente da resposta esperada pela escola.

Para aprender o aluno deve superar as dificuldades cognitivas, e podem surgir novos problemas, os problemas de aprendizagem. Compreender o funcionamento destes obstáculos exige outra concepção teórica. (...) O desejo impulsiona o aluno no sentido de buscar novos conhecimentos, superando as dificuldades cognitivas, mas pode servir como um obstáculo quando atribui uma significação inconsciente ao conteúdo ensinado pala escola (CORRÊA, 2001, p. 156).

Na tentativa de superação das dificuldades do processo de ensino-aprendizagem é que o Ensino de Ciências se apresenta como um desafio enorme, principalmente quando se leciona tanto na Educação Básica (anos finais do Ensino Fundamental), quanto na Educação de Jovens e Adultos (EJA). Como já citado, este trabalho também reflete o período de estágio de regência em que as autoras lecionaram nestas duas modalidades de ensino ${ }^{1}$. Ao pensar a EJA é necessário compreendê-la:

\begin{abstract}
Enquanto espaço de garantia de direito à educação e efetivo exercício de cidadania para aqueles e aquelas que não tiveram o direito à leitura, à escrita e à interação com o conhecimento, torna-se desafiador entender e intervir nos processos que condicionam o acesso e a permanência das mulheres, mas também os aspectos que, uma vez no espaço escolar, não promovem nos homens e mulheres estudantes reflexões críticas sobre as hierarquias sociais estabelecidas (SILVA, 2010, p. 78).
\end{abstract}

A EJA cumpre papel fundamental na garantia do direito a escolarização e também exerce a função de ser este espaço do exercício da cidadania. Morais (2009), afirma que "a ausência da educação escolar representa uma grande lacuna para o indivíduo e uma perda enorme para a cidadania", ainda mais se tratando da realidade do campo na qual inúmeros sujeitos têm este direito negado e os altos índices de analfabetismo e de baixa escolaridade ainda não atingiram o status de uma educação de qualidade, acessível e que diminua as desigualdades socioeducativas.

Pensar a leitura da escola do campo e o Ensino de Ciências é pensar no processo de ensinoaprendizado como construção possível da cidadania e também de um processo dinâmico, contextualizado, condizente com a realidade. Morais (2009) afirma que:

O Ensino de Ciências e Biologia deve proporcionar ao aluno de EJA a oportunidade de visualização de conceitos ou de processos que estão sendo construídos por ele na escola, pois a missão da educação é conduzir o crescimento intelectual, moral e ético da comunidade através de ensinamentos, exemplos, experiências levados à escola, fazendo com que cada um se conscientize e se responsabilize pelo destino da sua própria vida (p.2).

\footnotetext{
${ }^{1}$ Além de atuarem no Ensino Fundamental e na EJA, houve a inserção no processo de ensino-aprendizagem do Programa "Mais Educação", este programa "é uma política de educação nacional que prevê a oferta de atividades socioeducativas no contraturno escolar, apostando que as ampliações do tempo e dos espaços educativos possam ser a solução para os problemas da qualidade de ensino, bem como se apresentam como estratégia de combate à pobreza, à exclusão social e à marginalização cultural" (ROSA, 2012).
} 
O terrário como possibilidade de construção de um laboratório vivo pode se tornar um ensinamento significativo dentro do Ensino de Ciências, já que muitos discentes e professores pela sua própria experiência de vida e de vivência em uma escola do campo levarão a construção de um miniecossistema condizente com a sua realidade.

\subsection{Terrário e o Ensino de Ciências}

Segundo Botelho (2008), o Terrário é um dispositivo experimental que reproduz um ambiente natural. Uma vez que sua constituição não segue padrão obrigatório, podemos considerar pertinente a ele o que se deseja estudar. Dessa forma, a busca de soluções alternativas no Ensino de Ciências inspirou a construção de um terrário como motivação que permita conduzir o processo ensino aprendizagem.

Continuando com a descrição de Botelho (2008), que o terrário é a elaboração de atividades teóricopráticas criadas a partir da construção de um Terrário como dispositivo de um meio natural, as variações ambientais produzidas neste ambiente, poderão ser previstas, introduzidas, observadas e estudadas pelos discentes. Encontramos ainda a afirmação de que o ensino de Ciências contempla um conjunto de "Ciências".

Sendo que a proposta da construção de um terrário visa propiciar envolvimento dos discentes através da observação, experimentação, e exploração de atividades diferenciadas que possibilite uma melhor compreensão de conceitos pertinentes ao ensino de Ciências através da interação dos conteúdos.

Os Terrários apresentados como modelos de Ecossistemas terrestres constituem-se de mini laboratório prático, através dos quais se procura reproduzir as condições do meio ambiente. São montados em pote (caixa de vidro tipo aquário), onde são depositados cascalho, areia, terra preta, pequenas plantas e animais assim como um pequeno recipiente com água (ROSA, 2009).

Tal qual um "mundo em miniatura", o terrrário procura reproduzir o ambiente natural onde vivem certos animais e plantas.

Uma formiga que se movimenta dentro de um terrário, está na mesma proporção que um homem no meio de uma selva. A instalação dessas pequenas comunidades ajuda o estudo e a compreensão de como vivem as plantas e os animais. Em contato com a Natureza, é possível observar diferentes tipos de flora e de fauna. Os organismos que vivem nas regiões secas e quentes do deserto adaptam-se às temperaturas extremamente altas e à falta de água. As plantas e os animais que se desenvolvem nas regiões pantanosas não poderiam sobreviver num deserto, pois necessitam temperaturas mais amenas e maior quantidade de água. (Programa de Ciência exitus enciclopédia ilustrada 1975, p.1740-1741, vol. IX).

Segundo outro dicionário de Ciências Existus (1975, p.260) a palavra Terrário origina-se de terra + ário, por analogia com aquário. Lugar, nos jardins zoológicos, providos de terra, pedras, rochas e plantas, para criação ou exposição de animais. Compõe uma comunidade vivente em miniatura, com perfeito equilíbrio natural entre as suas várias características, e com um ambiente específico, intencionalmente criado.

\section{Materiais e Métodos}

\subsection{Descrição da escola}

Em 1963 foi construída a primeira escola no distrito de Irenópolis, com o nome Escola Estadual $1^{\text {o }}$ grau Senador Filinto Muller. Hoje o nome é Escola Estadual de Educação Básica Senador Filinto Muller (Figura 1). Este trabalho foi desenvolvido na Escola que atua como um centro Educacional de Ensino, "Escola do Campo". Localizada no Distrito de Irenópolis, no município de Juscimeira-MT, esta escola recebe discentes das fazendas, sítios, chácaras, assentamento e da população local. 
A Política Educacional é voltada para uma qualidade de Ensino que busca resgatar os valores éticos e morais, trabalhando a valorização do ser humano e resgatando as diversidades culturais. A escola funciona nos três períodos: matutino, vespertino e noturno, atende ao Ensino Fundamental, a EJA e Ensino Médio, com aproximadamente 120 discentes. O Ensino Fundamental é constituído por 33 discentes matriculados, e na EJA do segundo segmento por 13 discentes matriculados. A escola possui 13 professores de diversas áreas de conhecimentos.

A estrutura física da escola está em bom estado de conservação, tendo: 01 Biblioteca, 04 salas de aulas, 01 refeitório, laboratório de informática, quadra de esporte e uma Horta Pedagógica que é utilizada e cuidada pelos discentes do Programa Mais Educação.
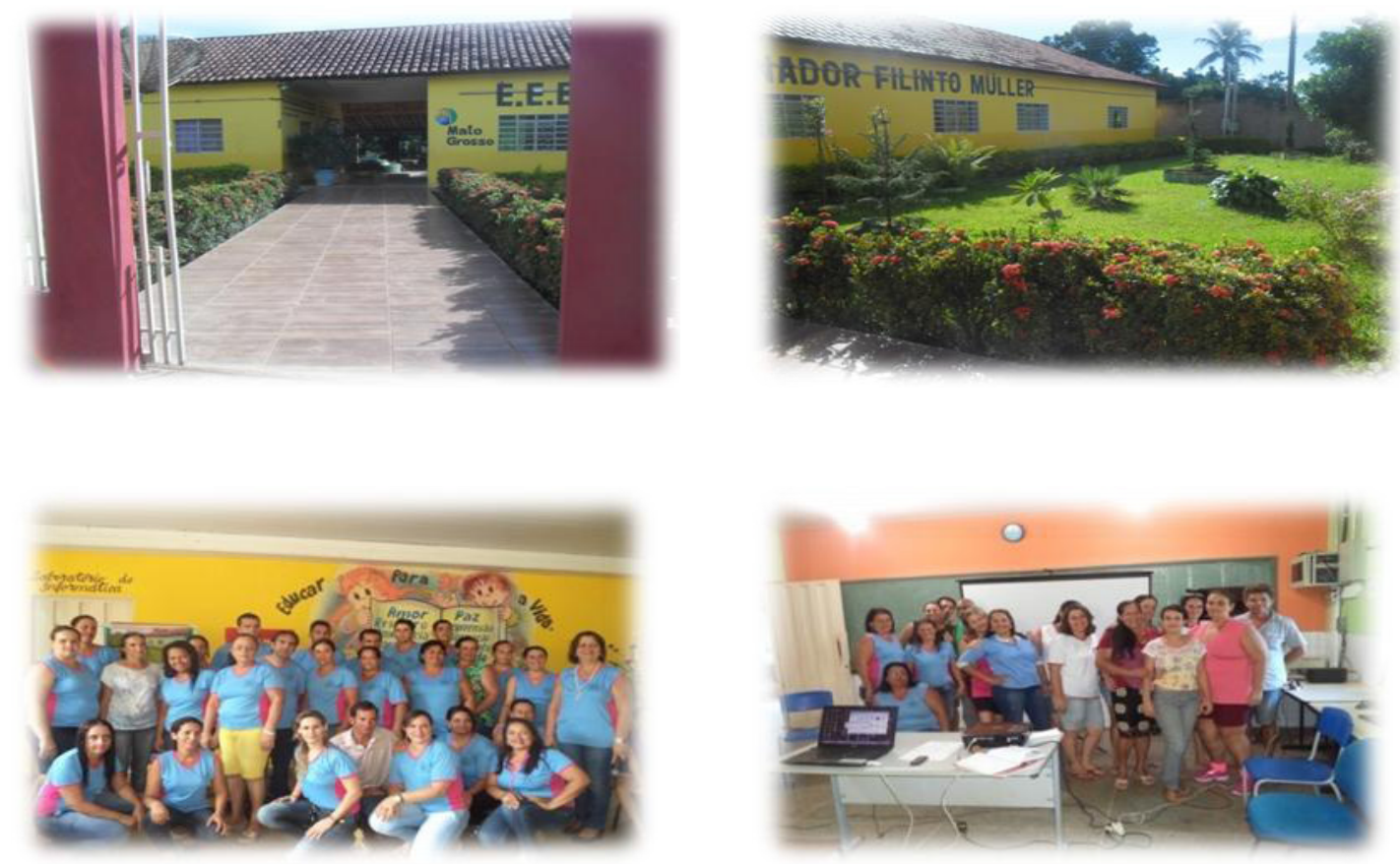

Figura 1. Vista da frente da escola e dos profissionais da educação que atuam na mesma.

\subsection{Caminho Metodológico}

O tema do trabalho foi a construção do Terrário com os discentes do Ensino Fundamental do Programa Mais Educação e outro Terrário com a EJA do segundo segmento, servindo assim como prática para auxiliar na aprendizagem significativa. Concordamos com Caldart que afirma que "para se fazer uma escola do campo é preciso olhar para as ações ou práticas sociais que são constitutivas dos sujeitos do campo" (2000, p. 75).

As aulas foram voltadas para a construção dos Terrários, as explicações das aulas foram elaboradas de acordo com o conteúdo do Terrário e com o conteúdo do professor regente na escola durante o estágio curricular das autoras Laylla e Layanne de Licenciatura em Ciências da Natureza. Os planos de aulas foram elaborados em conjunto com a professora regente da escola do Ensino de Ciências, a coordenação e as autoras do trabalho.

A intervenção do projeto foi realizada com a turma do Programa Mais Educação no período vespertino, na terça-feira das 13:00 às 16:00 horas, e nas quinta-feira das 13:00 às 15:00 horas. Teve início no dia 05 de maio de 2015 e terminou no dia 02 de junho de 2015, totalizando 23 horas de intervenção. Nesta ação foram reunidas todas as turmas do Ensino Fundamental. 
Na turma da EJA do segundo segmento, tivemos pouco tempo juntos, mas foi muito divertido. O trabalho teve início no dia 07 de maio de 2015 e prosseguiu até o dia 29 de maio de 2015, na quintafeira duas horas, e na sexta-feira apenas uma, por semana 3 horas. A intervenção foi feita durante a regência, estágio nas aulas de ciências, no período noturno. O questionário era feito com os discentes

presentes, mas como vinha poucos discentes, assim que aparecessem discentes novos na outra aula, antes da explicação, aplicávamos o questionário aos mesmos.

Durante as aulas foram apresentados os conteúdos por meio de slides, assim como o projeto da construção do Terrário. Os discentes foram questionados previamente sobre suas concepções de Terrário. As ações foram avaliadas segundo a aprendizagem antes e depois das práticas. Também foram desenvolvidos jogos educacionais, dinâmicas, entre outras programações que poderiam surgir no decorrer do desenvolvimento desse trabalho.

No primeiro momento foi entregue aos discentes um questionário sobre Terrário. As perguntas foram guardadas e apresentadas para os mesmos no final da experiência, para cada discente perceber seus erros ou acertos, refletir sobre o tema abordado e construir assim o conhecimento sobre o Terrário.

Logo após o questionário, foi ministrada uma aula teórica, com apresentação de slides. Em seguida, foi proposto como aula prática a construção do terrário, o que envolveu a participação de todos os discentes, sem exclusão.

Após a construção do terrário foi promovida uma roda de conversa, para que os discentes opinassem sobre o que vai acontecer com o mini-ecossistema com o decorrer do tempo. A coleta de dados foi obtida através da observação e análise do Terrário, a resolução de alguns questionários e da participação dos discentes nas atividades.

\subsubsection{Passos Metodológicos:}

Passos metodológicos do Ensino Fundamental:

Passo I - Questionário prévio sobre Terrário e Construção de uma trilha pedagógica sobre ecossistema.

Passo II - Construção do Terrário.

Passo III - Observação do mesmo.

Passo IV- Aula Teórica sobre o Terrário e Ecossistema. Exercícios sobre os Temas.

Passo V- Dinâmicas e atividades sobre o assunto.

Passo VI - Resolução novamente do primeiro questionário.

Passos metodológicos da EJA do segundo segmento ( $8^{\circ}$ E $9^{\circ}$ Ano):

Passo I - Questionário prévio sobre terrário e construção de cartazes com colagem sobre ecossistema.

Passo II - Construção do Terrário.

Passo III - Observação do mesmo.

Passo IV - Aula teórica sobre o Terrário e exercícios sobre o tema.

Passo V - Resolução novamente do primeiro questionário.

\subsection{Materiais utilizados}

Nas aulas: computador, data show, folha A4, caderno, livros, lápis ou caneta, lápis de cor e canetinhas, borracha, cola, cartolinas, tesouras, jogos educacionais, entre outros. Na construção do Terrário: aquário, cascalho, areia, carvão, terra humosa, plantas diversas, galhos secos, minhoca, pequenos animais, plástico insulfilme, água, algumas ferramentas para mexer a terra, alguns animais de plásticos para simbolizar animais de grande porte, casas ilustrativas, entre outros. 


\section{Resultados e Discussões}

\subsection{Resultados do ensino fundamental}

No dia 05 de maio de 2015, no primeiro dia de intervenção houve uma conversa dirigida com os discentes, conhecendo um pouco sobre a vida dos mesmos. Depois foi aplicado o questionário sobre o Terrário. Para averiguar os conhecimentos prévios sobre o tema foram mostradas imagens do que é o Terrário. Os discentes ficaram de certa forma surpresos, pois desconheciam um Terrário. No questionário aplicado havia três questões, sendo a primeira: O que é um Terrário? A segunda: Para que serve um Terrário? E a última: Quais os materiais utilizados na construção do Terrário e quais são os procedimentos?

Na primeira questão (O que é Terrário?) de um total de 12 discentes do ensino fundamental, 8 discentes responderam que o Terrário era terra, 2 discentes responderam que era um recipiente onde se colocava terra, e outros 2 discentes responderam que era um terreno.

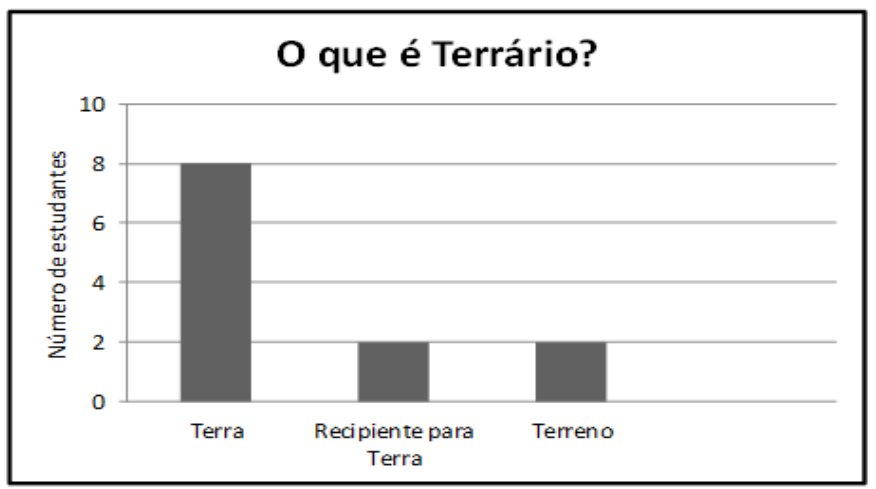

Figura 2 - Resultados da primeira questão do questionário prévio aplicado aos discentes sobre o Terrário.

Na segunda questão (Para que serve o Terrário?), seis discentes responderam que o Terrário serve para cultivar plantas, 01 discente respondeu que serve para andar em cima, 1 discente respondeu que servia para jogar no canteiro. Um discente respondeu que servia para fazer coisas de enterros e outro discente respondeu que servia para criar gado. Dois discentes responderam que servia para aterrar terrenos.

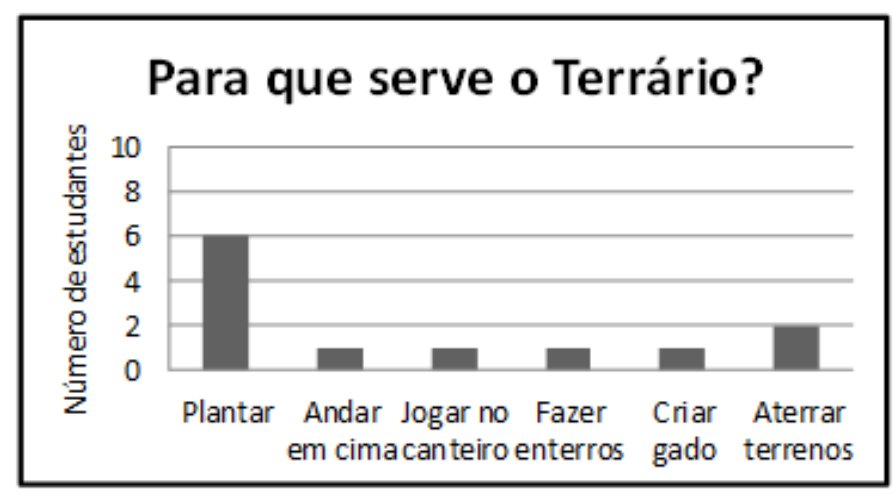

Figura 3 - Resultados da segunda questão do questionário prévio aplicados aos discentes sobre o Terrário.

$\mathrm{Na}$ terceira questão, os 12 discentes não souberam responder adequadamente quais os materiais utilizados na construção do Terrário e quais são os procedimentos. 
No momento seguinte, os discentes foram separados em dois grupos: o grupo das meninas e o dos meninos. Os discentes recortaram figuras relacionadas com o ecossistema. Depois os mesmos fizeram colagem, montando cada grupo um cartaz com as imagens, formando um ecossistema. Por fim construímos juntamente com os discentes, uma trilha pedagógica, com o tema ecossistema. Cada discente elaborou 10 questões com respostas para a brincadeira, e auxiliamos na montagem das regras do jogo. Na trilha, cada discente colou uma imagem de um animal que silvestre. Neste dia pedimos que os discentes trouxessem para a próxima aula uma garrafa pet, e uma planta de pequeno porte.

Para a construção do Terrário, as plantas que iríamos utilizar foram colhidas nas casas de vizinhos (Figura 04).
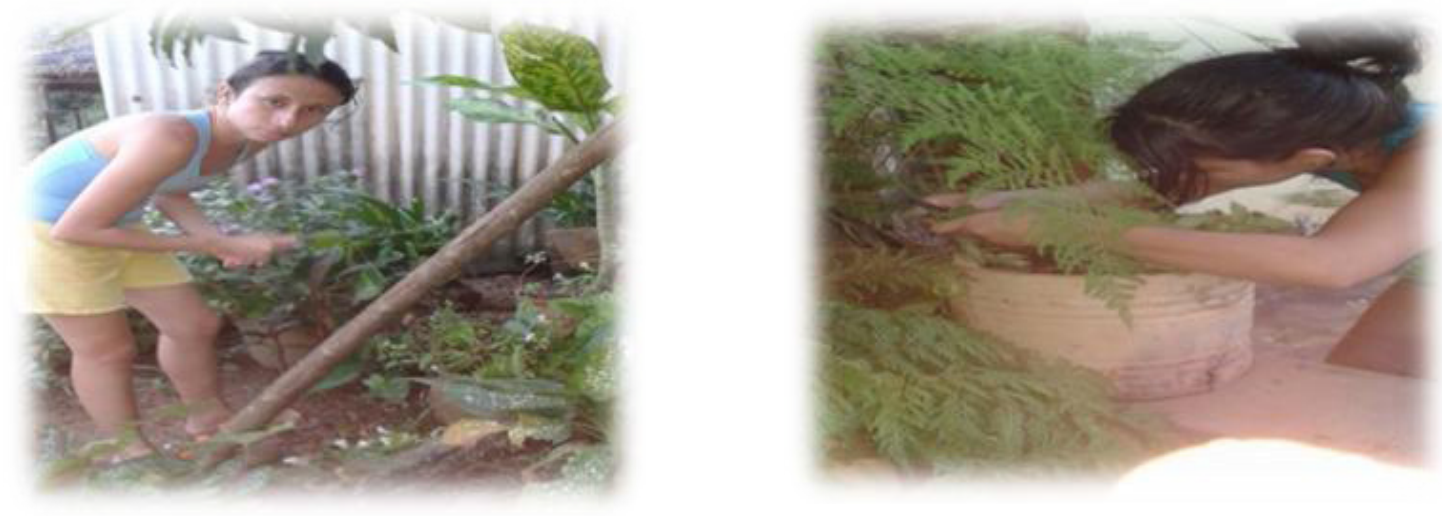

Figura 4 - Plantas colhidas no entorno da comunidade e nas casas de vizinhos da escola.

No dia 07 de maio de 2015, ocorreu a construção do Terrário. Primeiramente construímos um miniecossistema com as garrafas pet e uma planta de pequeno porte (Figura 05). Cada discente fez o seu Terrário. Depois construímos juntos um Terrário em um aquário (Figura 06). Os materiais utilizados foram trazidos por nós, trouxemos também pequenos animais como: poiolho de cobra (Lulus sabulosus cylindroiulus), esperança (Tettigonia viridissima), aranhas, minhocas e tatu-bola de jardim (Armadillidium vulgare).
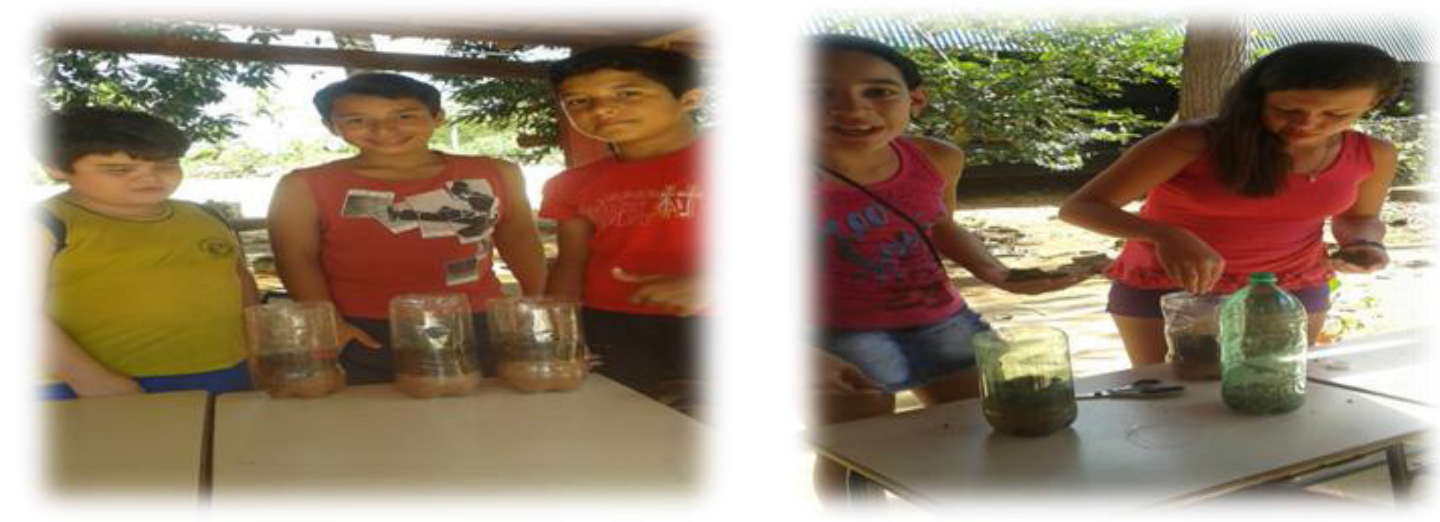

Figura 5 - Construção individual do Terrário em uma garrafa pet com os discentes do Programa Mais Educação.

A construção do Terrário, além de ser uma atividade que interliga a dimensão ambiental nas escolas, propicia a interdisciplinaridade entre as áreas do conhecimento e contribui para a elaboração de materiais didático-pedagógicos condizentes com a realidade de cada escola-comunidade. Neste sentido, ao avaliar as políticas públicas de Educação Ambiental, Pedrotti-Mansilla (2010) afirma que: 
As dificuldades para inclusão da EA nas escolas são sublinhadas principalmente pela ausência de materiais pedagógicos, o que orienta a formulação de políticas públicas que estimule a produção de materiais locais com ampla divulgação como plataforma das políticas de EA. Um segundo problema concentra-se na escassez de processos formativos, iniciais e continuados, que acarreta diversos outros problemas como: inabilidade em se trabalhar em grupo ou formar parcerias; redimensionar o currículo às temáticas transversais; compreender os conceitos subjacentes ao campo da EA; fomentar a participação comunitária nos projetos da escola; e a enorme dificuldade em se avaliar a aprendizagem no âmbito da EA, já que, por ser uma proposta de vanguarda e incorporada tardiamente pelos sistemas formais de educação, os modelos de avaliação tradicionais não conseguem abarcar o processo da formação de uma comunidade de aprendizagem (p.39).
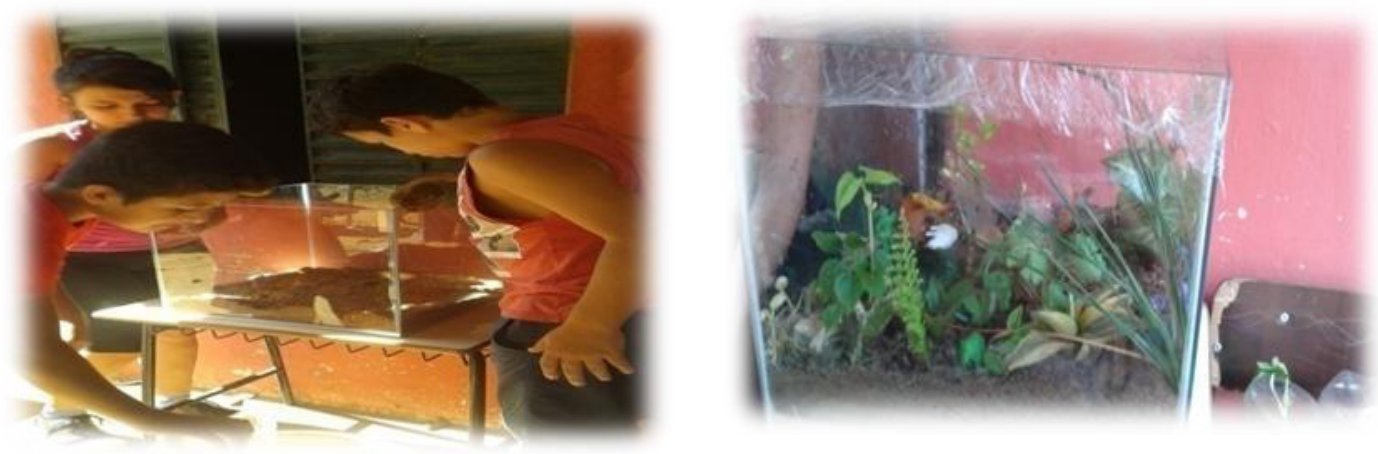

Figura 6 - Construção coletiva do Terrário em um aquário com os discentes do Programa Mais Educação.

Neste mesmo dia os discentes da sala multi-ciclada (unidocência do $4^{\circ}$ e $5^{\mathrm{o}}$ ano), ficaram curiosos para ver a atividade prática que foi realizada. Depois da construção do Terrário, pedimos autorização ao docente da turma e levamos os mesmos também para observar e explicitamos alguns conceitos sobre a temática. Os discentes ficaram impressionados com aquela experiência, foi maravilhoso ver aqueles pequenos estudantes interessados pelo Terrário.

No dia 12 de maio de 2015, primeiramente fomos com os discentes do Ensino Fundamental ( $6^{\mathbf{o}}$ ao $9^{0}$ ano) observar o Terrário. Muito interessante ver a curiosidade dos discentes pela nossa experiência. Ficaram empolgados para observarem o que havia acontecido com o Terrário. Os discentes fizeram um relato de tudo o que ali havia acontecido. Depois fomos para a biblioteca, para uma aula com apresentação de slides, sobre Terrário, ecossistema, ciclos biogeoquímicos e a cadeia alimentar.

Neste dia notamos que os discentes não gostam de aulas com slides, acham cansativas, quase não prestam atenção. Eles falaram que aula é de manhã, a tarde ele gostam apenas de brincadeiras, porque é cansativo estudar cedo e a tarde também. Após a explanação dos conteúdos, distribuímos desenhos, cruzadinhas, um alfabeto ecológico, entre outros, relacionados com Terrário e com o ecossistema.

Por isto, a proposta em se trabalhar com Projetos Ambientais Escolares Comunitários - PAEC representa um repensar o trabalho com os projetos nas escolas para se chegar "a ousadia em transformar as ações de intervenção educativa em processos de gestação educativa pelas próprias escolas e seu entorno" (MATO GROSSO, 2004).

No dia 14 de maio de 2015, fomos novamente observar o Terrário. Depois fomos para o refeitório, onde distribuímos uma atividade com 10 questões sobre a explicação da aula passada, sobre ecossistema.

No dia 19 de maio de 2015, foi realizada uma nova observação no Terrário. Neste dia apenas 02 discentes compareceram. Utilizamos duas trilhas pedagógicas: a trilha da vida e da sexualidade. A relação da trilha da vida com o Terrário, é que representa o ciclo da vida dos animais e do ser humano, vidas que podem estar presentes no Terrário, já a da sexualidade representa o valor reprodutivo do ser humano e dos animais para o ecossistema. Neste mesmo dia tivemos um visitante, Gilierme, que no final participou tocando violão e cantou músicas com os discentes. 
No dia 21 de maio de 2015, vieram 04 discentes. Primeiro foi realizada observação do Terrário. Logo após fomos para a biblioteca, recortar figuras e fazer colagem, construindo uma montagem com os ciclos biogeoquímicos, relacionados com os que acontecem no nosso Terrário.

No dia 26 de maio de 2015, com 04 discentes presentes, no primeiro momento fizeram a observação do Terrário, depois fomos para a biblioteca. Trouxemos uma dinâmica diferente, pois ensinamos os discentes a fazerem um sapo de dobradura. Esse animal representaria todos os animais que vivem no nosso ecossistema. O sapo de dobradura foi feito no papel A4. Depois cada um coloriu o seu, e em seguida colamos esses sapos em um cartaz. Foi atribuído 10 pontos para quem conseguisse fazer o sapo sozinho. Quem pedisse ajuda iria perdendo os pontos. Apenas 01 discente pediu ajuda. Esses sapos foram levados pelos discentes como recordação da nossa aula.

Em seguida brincamos de várias dinâmicas na quadra de esporte da escola relacionadas com o ecossistema. Uma das dinâmicas foi a de falar nomes de animais que vivem no ecossistema, repetindo os nomes dos animais que foram falados pelos colegas. Os discentes não podiam esquecer os nomes dos animais, quem esqueceu saiu da brincadeira. Depois brincamos com a bola. Em cada passada de bola para o colega era dita uma letra do alfabeto. Quem deixasse a bola cair teria que falar um nome de um animal e uma fruta com a inicial da letra do alfabeto. Por último brincamos de mímicas com o grupo das meninas e outro dos meninos. Foram muito engraçadas as mímicas feitas pelos discentes, rimos bastante. Este dia foi feito a última observação do Terrário. Os discentes fizeram 05 observações no Terrário.

No dia 28 de maio de 2015, vieram 08 discentes. Destes, 03 nunca tinham vindo. Então tivemos que dar uma explicação sobre nosso trabalho e do Terrário. Este dia foi para desmanchar o Terrário, com a participação dos discentes. Depois os discentes resolveram novamente o primeiro questionário sobre o Terrário. Todos esses discentes conseguiram responder corretamente o questionário. Portanto, tiveram uma aprendizagem significativa do nosso trabalho. Em seguida cada discente pegou uma planta que estava no Terrário para plantar em um canteiro da Escola (Figura 7).
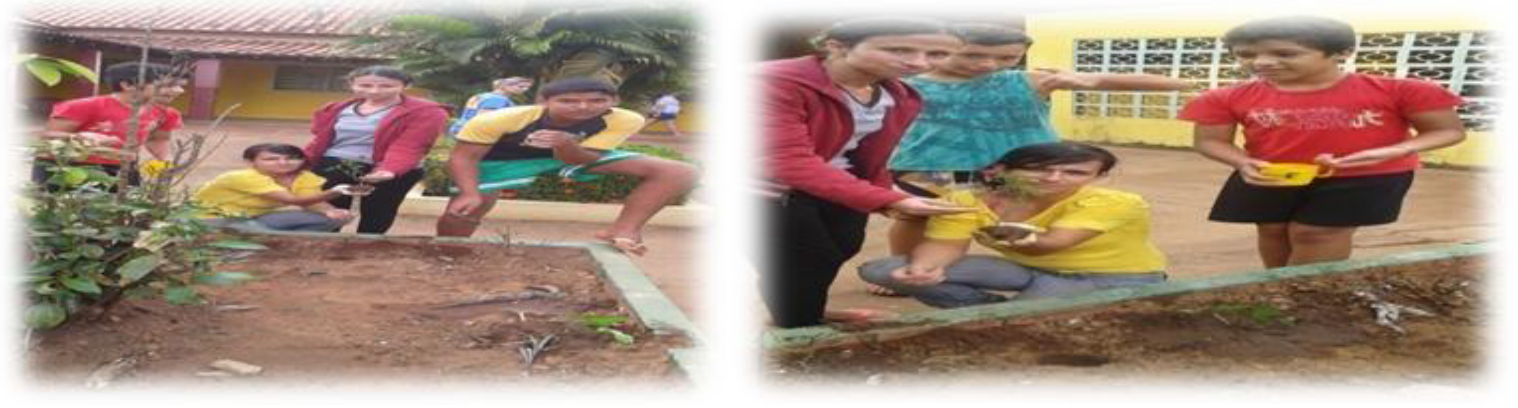

Figura 7- Plantio de plantas do Terrário no canteiro da escola.

Ao relatar sobre a Pedagogia da Alternância, Caldart (2000) explicita que um dos pressupostos do tempo escola é o momento em que os educandos devem ter "aulas teóricas e práticas, participam de inúmeros aprendizados, se auto-organizam para realizar tarefas que garantam o funcionamento da escola, avaliam o processo e participam do planejamento das atividades, vivenciam e aprofundam valores" (p.60). Mesmo que a escola de Irenópolis não tenha a Pedagogia da Alternância como metodologia, acreditamos que estas intervenções pedagógicas e projetos possam trabalhar estas atividades diversificadas e aprofundar alguns valores ambientais e comunitários.

No dia 02 de junho de 2015, com a presença de 12 discentes, fizemos a nossa despedida. Brincamos com a trilha pedagógica construída pelos discentes no primeiro dia de intervenção. Com isto, conseguimos trabalhar seguindo a lógica da aprendizagem remetendo conhecimentos novos aos anteriores, e assim, encerramos nossa intervenção com a turma do Programa Mais Educação.

Pode-se perceber como o processo de intervenção foi válido e realmente houve uma construção do conhecimento. Depois da intervenção, estávamos na biblioteca da escola lendo livros, apareceu um 
discente do Ensino Fundamental que não teve a oportunidade de participar da construção do Terrário, Olívio Pedro, e nos perguntou: - Professoras, o que aconteceu com aquele Terrário que estava lá no fundo da escola? Quando íamos responder apareceu um discente chamado Hugo, que havia participado, então falamos: - Por favor, Hugo, explique para seu colega o que aconteceu no Terrário. O discente Hugo explicou corretamente tudo o que havia acontecido com o Terrário.

O discente Olívio Pedro ficou encantado e disse: - Hum, que legal, que pena que não pude participar, mas vou fazer um em casa para eu ver o que acontece. É maravilhoso ver que um discente que não participou da construção do Terrário ficou interessado com o trabalho, despertou a curiosidade de ver o que havia acontecido ali. E é mais gratificante ainda ver o discente Hugo explicar tudo o que a gente havia ensinado, notamos que esse discente teve uma aprendizagem significativa e temos certeza que ele jamais vai esquecer-se dessa experiência, feita por nós na escola Senador Filinto Muller.

\subsection{Resultados da EJA}

No primeiro dia, dia 07 de maio de 2015, vieram apenas 05 alunas, quatro senhoras de idade e uma com aproximadamente uns 17 anos. Apresentamo-nos, explicamos o que estávamos fazendo ali, depois cada um falou um pouco sobre sua vida pessoal. Logo após aplicamos o questionário sobre Terrário, todas ficaram curiosas para saber o que era esse tal de Terrário, foi impressionante.

Neste questionário tinha 03 questões, a primeira: O que é Terrário? A segunda: Para que serve um Terrário? E a última: Quais os materiais utilizados na construção do Terrário e quais são os procedimentos?

Na primeira questão (O que era Terrário?) 03 discentes responderam que "não sabia o que era $o$ Terrário", 01 respondeu que era "um monte de terra feito uma ilha", outra aluna respondeu que "eram várias terras juntas", e 01 respondeu que "era um lugar plano". Na segunda questão (Para que serve o Terrário?) 03 discentes responderam que "não sabia para que servia o Terrário", 01 respondeu que "servia para plantar", outra respondeu que "servia para pessoas morar". Na terceira questão (Quais foram os materiais utilizados na construção do Terrário e quais são os procedimentos?) as discentes não souberam responder. Isto demonstra que, se as discentes desconhecem o conceito do que é um Terrário, muito menos saberão o que é necessário para a sua construção.

Depois dos questionários prontos, levamos às discentes no fundo da escola onde estava o Terrário da turma do Programa Mais Educação. Com uma lanterna, todas as alunas ficaram surpresas e riram bastante porque elas não sabiam o que era, pois Terrário era uma coisa tão simples de explicar. Retornamos para a sala de aula, e explicitamos sobre os conceitos inerentes à temática. Uma aluna disse que "era muito bom participar de uma aula diferente", pois eles só fazem tarefas, nunca tinha nada diferente, e que as aulas ficavam cansativas.

Os momentos do estágio curricular e a intervenção pedagógica (construção do terrário) proposta pelas autoras é uma ótima oportunidade para se aproximar as instituições de Ensino Superior e a população a processos de educação popular, entretanto, não são suficientes. A EJA tem o seu ápice nos processos da educação popular e esta influencia muito pouco em uma relação dialética para mudança das metodologias das instituições.

Os estágios curriculares e a prática departamental da extensão universitária tem se revelado insuficientes para
favorecer a dinamização da vida universitária numa perspectiva de educação popular, uma vez que tendem a
estabelecer uma relação unidirecional da universidade para com a comunidade, da teoria para a prática. A
ligação dos projetos acadêmicos com as organizações populares apresenta-se, então, como um fator importante
para a evolução crítica de ambos, referencial concreto da prática social para sua elaboração, as organizações
populares podem assimilar referenciais científicos que permitam sistematizar sua práxis (FLEURI, 2009, p.104).

Após a explanação dos conceitos e a visualização do Terrário, os discentes fizeram um cartaz representando o ecossistema com figuras recortadas. Essas discentes cortaram tantas figuras que o cartaz ficou pequeno, não teve espaço para colocar os nomes das mesmas.

No dia 13 de maio voltamos à escola, e avisamos para a turma que na próxima aula trouxesse uma 
garrafa pet e uma planta de pequeno porte. Todos ficaram curiosos para saber o que iríamos fazer com aquilo. No dia 14 de maio de 2015, chegou o dia da construção do Terrário. Num primeiro momento entregamos para os dois dos cinco discentes que não estava na aula passada o questionário sobre o Terrário, depois levamos os dois para ver o Terrário da turma do Programa "Mais Educação" no fundo da escola com a lanterna.

Em seguida fomos para o refeitório para a construção do Terrário. Nós trouxemos os materiais para a construção: animais pequenos (aranha, minhoca, gongolo (L. sabulosus cylindroiulus), as plantas que foram doadas pela comunidade e pelos discentes, e alguns animais de plástico que tinha como finalidade representar animais ou objetos de grande porte, que não caberia no Terrário. Primeiramente, ensinamos a fazerem o Terrário na garrafa pet. Depois construímos junto o Terrário no aquário (Figura 8). Era um pouco pequeno, mas foi muito interessante ver a empolgação dos discentes. Este Terrário ficou de devolutiva para a escola. Outros discentes e funcionários da escola ficaram curiosos para ver o que a EJA estava fazendo. Esse Terrário ficou no refeitório para que outras turmas pudessem observar.
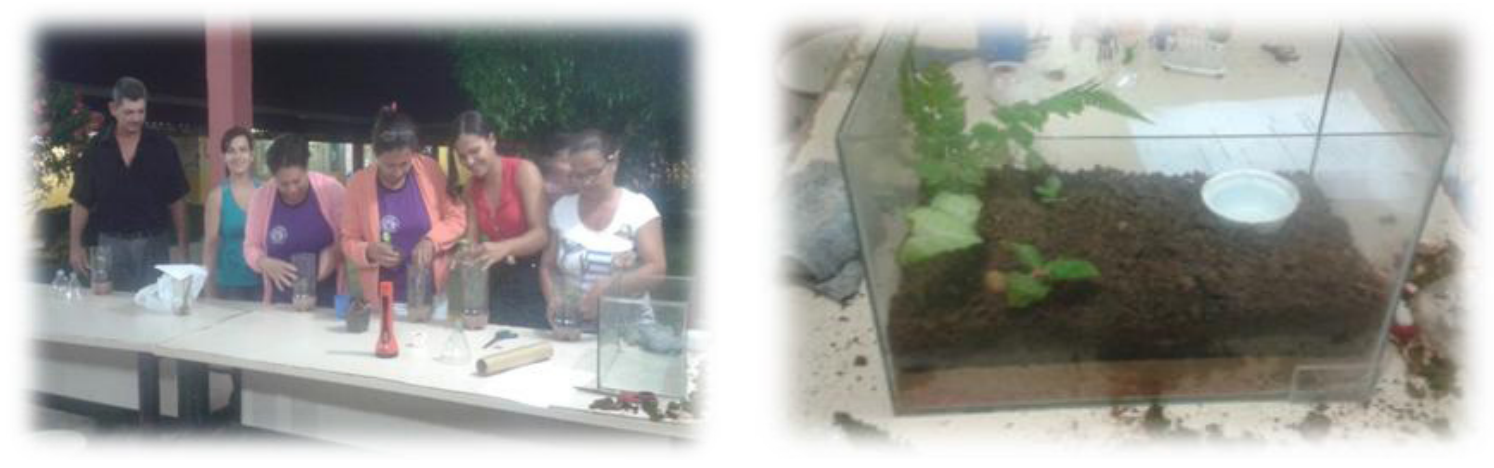

Figura 8 - Construção do terrário individual feito na garrafa pet e construção do terrário coletivo confeccionado em um aquário.

No dia 15 de maio de 2015, vieram 05 discentes. Nesta aula levamos os discentes para a informática para eles pesquisarem sobre Terrário e ecossistema. Alguns discentes não davam conta de pesquisar, assim a gente teve que ajudar esses discentes que tinha dificuldade de digitar, pesquisar, de conectarse na internet. Foi prazeroso mostrar e ensinar para esses discentes como utilizar o computador para várias atividades, sendo que muitos desses discentes não têm acesso.

No dia 21 de maio de 2015, fizemos a primeira observação do Terrário, com a presença de 05 discentes. Eles foram para o refeitório onde estava o nosso Terrário. Ali fizeram o relato do que havia acontecido. Após ouvir as histórias relatadas pelos discentes da EJA nós registramos as suas percepções e observações em uma folha A4. Depois voltamos para sala de aula, para aula teórica, apresentamos o conteúdo nos slides, sobre Terrário, Ecossistema, Ciclo Biogeoquímicos, Cadeia alimentar. Foi um pouco demorada a explicação, porque os discentes gostam de copiar tudo sobre o conteúdo dado.

No dia 22 de maio de 2015, vieram apenas 03 alunas. Na primeira aula foram distribuídos exercícios sobre a explicação do conteúdo da aula passada, contendo 10 questões. Pedimos que os discentes colassem todas as atividades no caderno, na disciplina de Ciências.

No dia 28 de maio de 2015, com a presença de 05 discentes. Fizemos a segunda e última observação do Terrário. Tivemos pouco tempo de trabalho com a EJA, mas este pouco tempo pode-se perceber que esta experiência nos marcou muito, devido ao desempenho dos discentes, a participação, a força de vontade de estudar que é impressionante. Depois fomos para a sala de aula para se trabalhar com atividades diversificadas, foram entregues atividades de: cruzadinha, sete erros, texto sobre a importância da água, entre outras. Todas as atividades estavam voltadas para a temática relacionada com o Terrário: ecossistema, cadeia alimentar e, os ciclos biogeoquímicos. Sobre as atividades diferenciadas e com respeito ao público da EJA Jaqueline Moll afirma que elas podem: 
Permitir conhecer a demanda das diferentes localidades e pensar estratégias locais para a solução dos problemas, de acordo com essas realidades, superando-se a ideia de unicidade metodológica e curricular. Nesta perspectiva é importante mapear os diferentes tipos de trabalhos educacionais com jovens e adultos (2001, p.208).

No dia 29 de maio de 2015, com a presença de 05 discentes. Aplicamos novamente o primeiro questionário sobre Terrário. Todos esses discentes deram conta de responder corretamente nosso questionário. Isso significa que nosso trabalho gerou resultados positivos, pois além do aprendizado do conteúdo houve também um processo de ensino-aprendizagem e uma experiência didática vivenciada pelos discentes da EJA.

Depois foi a hora de nos despedir da EJA. As autoras após realizar o estágio curricular chegaram a conclusão de que esta modalidade de ensino é a melhor turma que se tem para trabalhar, seja pelo fato dos discentes demonstrarem interesse em aprender, seja pelo fato do esforço individual e coletivo ficar evidenciado. Foi muito emocionante ver pessoas de mais idade, de mais experiência, gostar tanto do nosso trabalho.

\section{Considerações Finais}

Com a utilização da construção do Terrário como motivação de ensino, percebeu-se que os discentes tiveram uma aprendizagem significativa no Ensino Fundamental e na EJA. Verificamos que as aulas práticas contribuem para ampliar os conceitos científicos dos discentes. Portanto, todos esses discentes e as autoras aprenderam teorias e práticas relacionadas a uma experiência no Ensino de Ciências, tento a oportunidade de fazer aulas diferenciadas, de observação e análise do Terrário.

Sendo assim, terminamos com muita satisfação e orgulho este trabalho e percebemos o desafio que é trabalhar nas duas modalidades de ensino (fundamental e EJA). Outro aprendizado que se evidencia é que muitas vezes a realidade da escola do campo se apresenta com grandes desafios como: trabalhar com turma multi-ciclada; e adotar estratégias para se evitar a falta e evasão escolar dos discentes no processo de ensino-aprendizagem de uma forma geral. Mesmo assim, é possível se concretizar um Ensino de Ciências condizente com a realidade de cada escola-comunidade e de maneira significativa.

\section{Agradecimentos}

À Coordenação de Aperfeiçoamento de Pessoal de Nível Superior (CAPES) pelo subsídio através do Programa de Consolidação das Licenciaturas (PRODOCENCIA) Edital 019/2013, processo № 113.657, e do Programa Institucional de Bolsa de Iniciação à Docência (PIBID) Edital № 061/2013, processo № 128.570, IFMT/Campus São Vicente/Sub Projeto Ciências.

\section{Referências}

ALENCAR, José F. de. A professora "leiga": um rosto de várias faces. In: Educação e escola no campo / Jacques Therrien, Maria Nobre Damasceno coords. - Campinas: Papirus, 1993. - (Coleção magistério. Formação e trabalho pedagógico).

ALVES, Rubem. A alegria de ensinar. 6ํㅡㄹ edição. - São Paulo: Papirus, 2001.

ARROYO, Miguel Gonzalez. Políticas de Formação de Educadores (as) do Campo. In: Caderno Cedes, Campinas, vol.27, n.72, p.157-176, maio/ago. 2007. Disponível em http://www.cedes.unicamp.br.

BOTELHO, Lazara Aparecida. O Terrário como instrumento organizador da aprendizagem em Ciências do 9o ano. Programa de Desenvolvimento Educacional - PDE. Curitiba - Paraná, 2008. 
BRASIL. Secretaria de Educação Fundamental. Parâmetros curriculares nacionais: Ciências Naturais/Secretaria de Educação Fundamental. Brasília: MEC /SEF, 1998.

CORREAA, Rosa Maria. Dificuldades no aprender: um outro modo de olhar. - Campinas, SP: Mercado de Letras, 2001.

CALDART, Roseli Salete. A escola do campo em movimento. In: Projeto popular e escolas do campo / César Benjamin e Roseli Salete Caldart. - Brasília, DF: Articulação Nacional Por uma Educação Básica do Campo, 2000. Coleção Por uma Educação Básica do campo, no3.

DELIZOICOV, Demétrio. ANGOTTI, José André. PERNANBUCO, Marta Maria. Ensino de Ciências fundamentais e métodos. 3 ed. - São Pulo: Cortez, 2009.

FREIRE, Paulo. Pedagogia da autonomia: saberes necessários à prática educativa. São Paulo, editora Paz e Terra, 2011.

FREIRE, Paulo. Pedagogia dos Oprimidos. 44ª edição. - Rio de Janeiro: Paz e Terra, 2005.

FLEURI, Reinaldo Matias. CONVERSIDADE: extensão universitária e movimentos sociais. In: O popular e a educação: movimentos sociais, políticas públicas e desenvolvimento / org. Cristina Fiorenze, Telmo Marco. - Ijuí: Ed. Unijuí, 2009. -296p.

KRONBAUER, Selenir Corrêa Gonçalves. SIMIONATO, Margareth Fadanelli. Formação de Professores: abordagens contemporâneas. - São Paulo: Paulinas, 2008.

MATO GROSSO. Secretaria de Estado de Educação - SEDUC. Projeto de educação ambiental - PrEA: projeto ambiental escolar comunitário - PAEC / Secretaria de Estado de Educação - Cuiabá: Tanta Tinta, 2004. 104p. (Série Caderno, 4).

MOLL, Jaqueline. Políticas de educação de jovens e adultos no Brasil: desafios da contemporaneidade. In: Pesquisando e gestando outra escola: desafios contemporâneos / Rute Baquero; Cecília Broilo (organizadoras). São Leopoldo-RS, Editora Unisinos, 2001.

MORAIS, F. A. O ensino de ciências e biologia nas turmas de EJA: experiências no município de Sorriso-MT. Revista Ibero-Americana de Estudos em Educação, v.48, p.1-6, 2009.

PEDROTTI-MANSILLA, Débora Eriléia. Avaliando a Política de Educação Ambiental nas escolas do Mato Grosso: desafios entre os domínios da Governança e da Governabilidade. Tese de Doutorado Programa de Pós-Graduação em Ecologia e Recursos Naturais, UFSCAR, 2010.

ROSA, Rosane T. N. da. Terrário no ensino de ecossistemas terrestres e teoria ecológica. Revista Brasileira de Educação Científica e Tecnológica. v. 2, núm. 1, p. 87- 104, jan/abr. 2009.

SILVA, Jerry Adriani da. Um estudo sobre as especificidades dos/as educandos/as nas propostas pedagógicas de educação de jovens e adultos - EJA: tudo junto e misturado! Belo Horizonte: UFMG/FAE, 2010.

TERRÁRIO. In: Departamento Editorial das edições melhoramentos, colaboração: POLILO, R. PEREIRA, A.T. TONELLA, A. HIDALGO, A. L. C. OLIVEIRA, A. A. Dicionário de Ciências Exitus. Mirador Internacional. São Paulo. 1975. 
TERRÁRIO. In: Companhia de melhoramentos. Programa de Ciência exitus enciclopédia ilustrada. São Paulo: Mirador Internacional, 1975. 4ª ed. Pág. 12. Vol. I. pág. 1740-1741. Vol. IX.

THERRIEN, Jacques. A professora rural: o saber de sua prática social na esfera da construção social da escola no campo. In: Educação e escola no campo / Jacques Therrien, Maria Nobre Damasceno coords. - Campinas: Papirus, 1993. - (Coleção magistério. Formação e trabalho pedagógico).

ZÔMPERO, A. F. LABURÚ, C. E. Implementação de atividades investigativas na disciplina de Ciências em escola pública: uma experiência didática. Investigações em Ensino de Ciências - V17(3), pp. 675-684, 2012. 